\title{
Studies on the effects of pretreatment on production hydrogen from municipal sludge anaerobic fermentation
}

\author{
Feng $\mathrm{Wu}^{1,2}$, Shao-Qi Zhou ${ }^{1,{ }^{*}}$, Yang-Lan Lai ${ }^{1}$, Wen-Jiao Zhong ${ }^{2}$ \\ ${ }^{1}$ College of Environmental Science and Engineering, South China University of Technology, Guangzhou, 510006, China; \\ ${ }^{2}$ Guangdong Provincial People's Armed School, Guangzhou, 510006, China. \\ Corresponding author: ${ }^{*}$ esqzhou@scut.edu.cn
}

Received 31 March 2009; revised 15 April 2009; accepted 21 April 2009.

\begin{abstract}
Municipal sludge was rich in organic matter, period of natural degradation was long and low efficiency, leachate would pollute underground water. In this paper, a comparative study of the ways of pretreatment with acid alkali treatment, heat digestion and ultrasonic treatment were done. The results showed that the dehydrogenase activity was increased, the SCOD (soluable chemical oxygen demand, SCOD) increased more than 2.47 2.83, 1.70 1.76, 2.6 2.77 times respectively. The hydrogen yield increased more than 11.5 12.2, 24.1 24.7, 34.2 $34.9 \mathrm{~mL}^{-1} \mathrm{~g}^{-1}$ (VS) respectively. The period of prohydrogen was shorten to $7.5,8.0,6.5 \mathrm{~d}$ respectively. The degradation rate was up to $72.04 \%$, $81.4 \%, 80 \%$ respectively, the methane concentration in the gas was close to "zero" and ultrasonic treatment was better than others. Gompertz model curve fitting on hydrogen production was carried out. All the values of correlation factor R2 were more than $\mathbf{0 . 9 7}$.
\end{abstract}

Keywords: Municipal Sludge; Pretreatment; Anaerobic Digestion; Biological Pro-Hydrogen

\section{INTRODUCTION}

The wastesolid treatment mainly includes filleading, compost and incineration. Filleading and heap in brief results in resource waste and pollute the body of water, even endanger the human health. Which don't attach to coincidence method of "circulation economy". The wastesolid anaerobic fermentation producted hydrogen develope a new road of wastesolid resource. And many research workers are interested in it $[1,2,3,4,5,6,7]$. Gomez [8] has study on the two stages of bio-hydrogen production, hydrogen production and methanogenic, using organic solid waste and slaughterhouse waste as substrate, high temperature activated sludge as inoculum.
Levin's study [9] showed the wooden fiber of delignification is a good hydrogen production substrate. Liliana [6] use anaerobic sludge to degraded organic solid waste and synthetic wastewater in UASB whose capacity is $3.85 \mathrm{~L}$, and produce hydrogen successfully. The volume content and hydrogen production rate of $\mathrm{H}_{2}$ is $47 \%, 99 \mathrm{~N}$

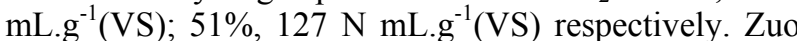
Yi [10] used river sediments as seed sludge, at the optimal condition of the $\mathrm{pH}$ of $5.0-5.2$, temperature of $35^{\circ} \mathrm{C}$, and HRT of 6-8 h, a steady anaerobic bio-hydrogen production was obtained in a lab scale reactor successfully with gluose as substrate. The highest hydrogen production was $6.7 \mathrm{~L} . \mathrm{d}^{-1}$. Tai Mulin [11] showed that the optimal initial $\mathrm{pH}$ for bio-hydrogen production from sewage sludge was around 11.0, Under this optimal condition, the bio-hydrogen yield of raw sludge was 8.1 $\mathrm{mL} \cdot \mathrm{g}^{-1}$, and it would reach to $16.9 \mathrm{~mL} \cdot \mathrm{g}^{-1}$ when the sludge was pretreated by alkali. Steven W. Van Ginkel [12] used food wastewater as substrate indicated Biogas produced from all four food processing wastewaters consistently contained $60 \%$ hydrogen, with the balance as carbon dioxide. Heguang Zhua [13] showed enhanced hydrogen production potential as compared with All combinations of the feedstocks (FW+PS, FW+WAS and $\mathrm{FW}+\mathrm{PS}+\mathrm{WAS}$ ). A mixing ratio of 1:1 was found to be the best among the ratios tested and hydrogen yield of $112 \mathrm{~mL} . \mathrm{g}^{-1}$ volatile solid (VS). M. Krupp and R. Widmann [14] studied Biohydrogen production by dark fermentation, the result showed The gas amount varied with the different OLRs, but could be stabilised on a high level as well as the hydrogen concentration in the gas with 44 52\%. Ela Eroglua [15] introduced Biological hydrogen production from olive millwastewater with two-stage processes. In some cases of dark-fermentation, activated sludge was initially acclimatized to the OMW to provide the adaptation of microorganisms to the extreme conditions of OMW. The highest hydrogen production potential obtained was $29 \mathrm{~L} \mathrm{H}_{2} / \mathrm{LOMW}$. Dongmin Li [16] used corn straw as substrate, Hydrogen was produced by simultaneous saccharification and fermentation from steam-exploded corn straw (SECS) using Clostridium butyricum AS1.209. 
Maximum specific hydrogen production rate and maximal hydrogen yield were $126 \mathrm{~mL} \cdot \mathrm{g}^{-1}$ (VSS) d and $68 \mathrm{~mL} \cdot \mathrm{g}^{-1}$ SECS, respectively. The yield of soluble metabolites was 197.7 mg.g ${ }^{-1}$ SECS. Acetic acid accounted for $46 \%$ of the total was the most abundant product and this shows that hydrogen production from SECS was essentially acetate-type fermentation.

Consequently, fermentative bio-hydrogen production technique is at the stage of laboratory research, many hydrogen production bottlenecks binding factors are urgently needed to be solved. This study focused on the factors of fermentative bio-hydrogen production of municipal sludge. In this paper, a comparative study on the effect of pretreatment-acid alkali treatment, heat digestion and ultrasonic treatment on hydrogen production were done, and the optimum pretreatment approach was ascertained, which break new a way for sludge treatment.

\section{MATERIALS AND METHODS}

\subsection{Source and Characteristic of Sludge}

Concentrated sludge came from a sewage treatment plant in Guangzhou, China. Table 1 showed The characteristics of the municipal sludge. In the experiment, the proper complement of N, P and inorganic micronutrients should be added in the sludge. The nutrient solution contained: $\mathrm{NH}_{4} \mathrm{HCO}_{3} 2.0 \mathrm{~g} \cdot \mathrm{L}^{-1}, \mathrm{MgSO}_{4} \cdot 7 \mathrm{H}_{2} \mathrm{O}$ $50 \mathrm{mg} \cdot \mathrm{L}^{-1}, \mathrm{NaCl} 10 \mathrm{mg} \cdot \mathrm{L}^{-1}, \mathrm{Na}_{2} \mathrm{MoO}_{4} \cdot 2 \mathrm{H}_{2} \mathrm{O} 10 \mathrm{mg} \cdot \mathrm{L}^{-1}$, $\mathrm{CaCl}_{2} \cdot 2 \mathrm{H}_{2} \mathrm{O} 10 \mathrm{mg} \cdot \mathrm{L}^{-1}, \mathrm{MnSO}_{4} \cdot 7 \mathrm{H}_{2} \mathrm{O} 15 \mathrm{mg} \cdot \mathrm{L}^{-1}, \mathrm{FeCl}_{2}$ $70 \mathrm{mg} \cdot \mathrm{L}^{-1}, \mathrm{KH}_{2} \mathrm{PO}_{4} 10 \mathrm{mg} \cdot \mathrm{L}^{-1}$.

\subsection{Experimental Equipment}

Cylindrical anaerobic reactor (patent number: ZL 20052 0053384.X) with the dimensions: $\emptyset_{\text {diameter }}=22 \mathrm{~cm}, \emptyset_{\text {external }}$ diameter $=24 \mathrm{~cm}, \mathrm{~h}=30 \mathrm{~cm}$, effective volume $=11$ liters; JY99-IID ultrasonic cell disruptor (Ningbo Xinzhi);
XLJ-IIB low-speed tabletop centrifuge (Shanghai an ting Scientific Instruments and Apparatus Co.); SC-15 thermostatic water-circulator bath box (Ningbo Xinzhi); JJ-4 digital display motor stirrer (Jintan City Zhengji Instruments Co. Ltd); BSD0.5 wet-gas flow meter (Shanghai Blue Jewelry); GC-7900 gas chromatograph, thermal conductivity detector, and FID detector (Shanghai Tianmei); ZXZ-1 sliding vane rotary vacuum pump (Zhejiang Huangyanqiujing, modified as shown in Fig. 1).

\subsection{Experimental Methods}

$1 \mathrm{~kg}$ dried sludge was dissolved in $10 \mathrm{~L}$ water, stirred uniformly, divided into A, B, C group. This sample would carry out acid alkali treatment, heat digestion and ultrasonic treatment, using 2\#, 3\#, 4\# to mark the sample performed cid alkali treatment, $5 \#, 6 \#, 7 \#$ to mark the sample performed heat digestion and $8 \#, 9 \#, 10 \#$ to mark the sample performed ultrasonic treatment. Put $200 \mathrm{~mL}$ the liquor in a cone type bottle as reference object which was marked 1\#. They were respectively performed anaerobic digestion in shaking table whose rate was 1,050 rpm at $36^{\circ} \mathrm{C}$.

\subsection{Analysis Methods}

Gas components were detected using a gas chromatograph (model: GC-7,900). A flame ionization detector (FID) and a 2-m stainless steel column packed with $5 \mathrm{~A}$

Table 1. Characteristics of condensed sludge from municipal wastewater treatment plan.

\begin{tabular}{ccccc}
\hline $\mathrm{pH}$ & $\begin{array}{c}\mathrm{SS} \\
(\mathrm{g} / \mathrm{Kg})\end{array}$ & $\begin{array}{c}\text { Water content } \\
(\%)\end{array}$ & $\mathrm{TN}$ & $\mathrm{COD}$ \\
\hline $6.7 \sim 7.9$ & $13 \sim 27$ & $78.7 \sim 90$ & $1750 \sim 2000$ & $3900 \sim 5000$ \\
\hline
\end{tabular}

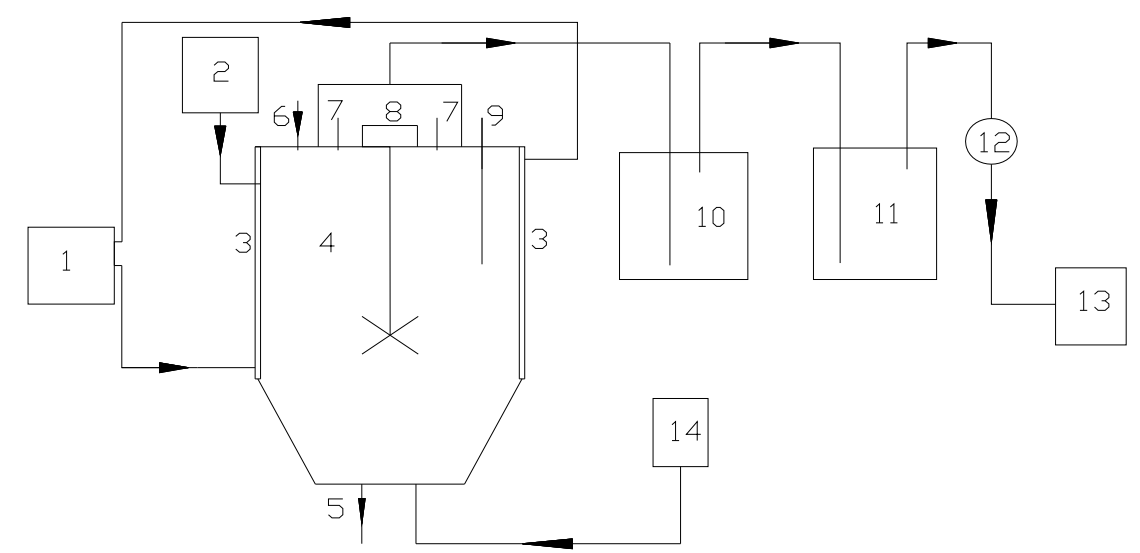

1. SC-15 water bath; 2. $\mathrm{pH}$ adjusting port; 3 . organic reactor; 4. agitating blade; 5 . reaction substrate outlet; 6. material inlet; 7. vent; 8. digital stirrer; 9. thermometer; 10. CO2 removal; 11. desiccant; 12. wet gas flowmeter; 13. GC-7900 gas chromatography; 14. nitrogen purging port.

Figure 1. Equipment and sequence of steps in the anaerobic digestion of sludge. 
Molecular Sieve were used to analyze the methane concentration. The temperatures of the injector, detector, and packed column were, respectively, 150, 180, and $100^{\circ} \mathrm{C} . \mathrm{H}_{2}$ was used as the carrier gas at a flow rate of 30 $\mathrm{mL} \cdot \mathrm{min}^{-1}$. The $\mathrm{N}_{2}$ flow rate was $30 \mathrm{~mL} \cdot \mathrm{min}^{-1}$ and the air velocity $260 \mathrm{~mL} \cdot \mathrm{min}^{-1}$. The hydrogen concentration was analyzed using a thermal conductivity detector (TCD) and a 2-m stainless steel column packed with 5A Molecular Sieve. The temperatures of the injector, detector, and packed column were, respectively, 180, 200, and $100^{\circ} \mathrm{C} . \mathrm{N}_{2}$ was used as the carrier gas at a flow rate of 29 $\mathrm{mL} \cdot \mathrm{min}^{-1}$. The injection volume was $10 \mu \mathrm{L}$. Quantitative analysis was carried out using external standards.

Otherwise, The quantity of chemical oxygen demand in sludge supernatant fluid was used to estimate the performance of sludge disintegration. The value of TCOD was equal to that of waste activated sludge supernatant fluid. The value of SCOD was equal to that of COD of sludge supernatant fluid which has been treated by centrifugal separation and filtration [17]. Determination of COD followed the standard methods [18]. The centrifuge worked for $20 \mathrm{~min}$ at $1,050 \mathrm{rpm}$, COD was determined according to International Standard [3]. Dehydrogenase activity of sludge was determined according to the method reported in the literature $[19,20]$.

\subsection{Cumulative Hydrogen Yield}

Cumulative hydrogen yield was estimated using the following equation $[21,22]$ :

$$
\mathrm{V}=\mathrm{V}_{0} \gamma_{\mathrm{i}}+\sum \mathrm{V}_{\mathrm{i}} \gamma_{\mathrm{i}}
$$

where $\mathrm{V}$ is the cumulative hydrogen yield $(\mathrm{mL}), \mathrm{V}_{0}$ the volume above the liquid level in the reactor $(\mathrm{mL}), \mathrm{V}_{\mathrm{i}}$ the volume of gas extracted in phase $\mathrm{i}(\mathrm{i}=1,2,3 \ldots)(\mathrm{mL})$, and $\gamma_{i}$ the concentration of hydrogen in the gas extracted in phase $i(i=1,2,3 \ldots)(i=1,2,3 \ldots)(\%)$.

\subsection{Kinetic Model of Hydrogen Production}

The Gompertz equation was used in the regression analysis of the anaerobic hydrogen production data in order to determine the lag time of hydrogen production, the hydrogen production potential, and the hydrogen production rate $[22,23]$ :

$$
H=P_{s} \exp \left\{-\exp \left[\frac{R_{s} e}{P_{s}}(\lambda-t)+1\right]\right\}
$$

where $\mathrm{H}$ is the cumulative hydrogen yield $(\mathrm{mL}), \mathrm{P}_{\mathrm{s}}$ the maximum hydrogen yield $(\mathrm{mL}), \mathrm{R}_{\mathrm{s}}$ the maximum hydrogen yield rate $\left(\mathrm{mL} \cdot \mathrm{h}^{-1}\right)$, and $\lambda$ the lag time of hydrogen production (h).

\section{RESULTS AND DISCUSSIONS}

\subsection{Effect of Acid and Alkali Treatment on Hydrogen Production}

Under normal temperature, the SCOD value of different sludge changed. $2 \#, 3 \#, 4 \#$ were used to mark the sludge $\mathrm{pH}=10,11,12$, respectively. $1 \#$ is control group, it is neutral. Fig. 2 showed the changes of SCOD value of sludge treated by acid alkali treatment. Fig. 3 showed the state of sludge anaerobic digestion bio-hydrogen production. Fig. 2 showed that the SCOD value of $2 \#$, $3 \#, 4 \#$ changed with time in the same regular but in different level: 9,266, 9,477, 10,624.5 mg. $\mathrm{L}^{-1}$. Compared with $1 \#$, The SCOD value of $2 \#, 3 \#, 4 \#$ were separately increased 2.47, 2.53, 2.83 times, The data indicated the dissolution of organic increased because of acid alkali treatment. The value of SCOD reached maximum at 24th hour, beginning to decrease at about 24-28th hour. The degradation rate was up to $72.04 \%$ from $60.4 \%$, increased by $12 \%$. The reason was that after the sludge was treated by acid alkali treatment, most of the organic has been dissolved, some of the difficult dissolved or-

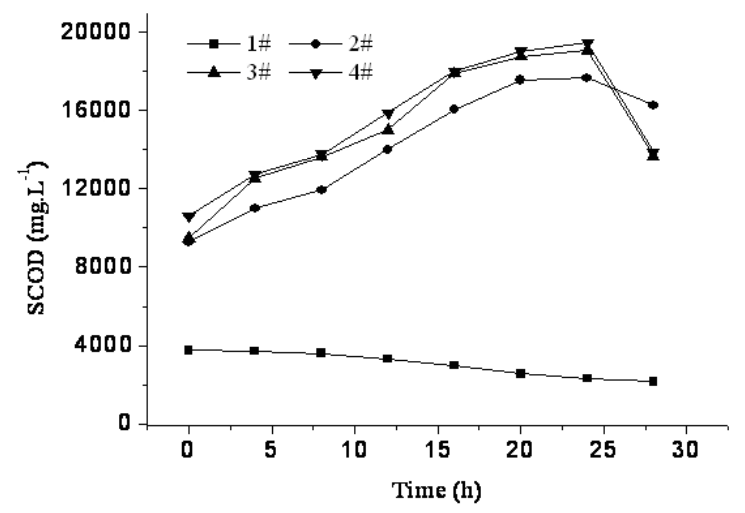

Figure 2. Change of SCOD about Sludge for anaerobic digestion.

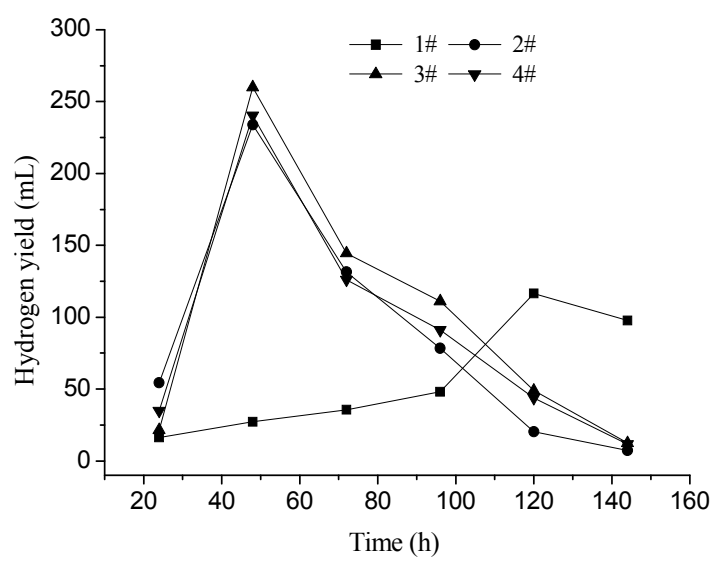

Figure 3. Change of hydrogen production about Sludge for anaerobic digestion ed and modified, and then solidified. 
ganic lignose, cellulose and hemicellulose etc had structural changes, hydrolyzed by cellulase, ligninase, etc. $24 \mathrm{~h}$ after start-up, almost all the organic absorbed by sludge has dissolved. The rate of organic dissolution was faster than that of bio-degradation result in the accumulation of organic in liquor, therefore, SCOD value rose obviously. 28 32 h after start-up, the number of biomass and live bacteria is max in the system. Plenty of carbon source was needed to maintain biological metabolism, so the anaerobic digestion speeded up, the organic was consumed by anaerobic bacteria as nutrient, and the COD started to decline. At the moment a large number of small bubbles attached to the conical flask because of biohydrogen bacterium starting to produce enormous hydrogen. In order to facilitate gas emissions, turn down the rate of shaking table to $1,050 \mathrm{rpm}$ to reduce gas-liquid interface pressure. The peak hydrogen productionin was observed at 32-48th hour, then the sludge hydrogen production ability weakened gradually, and the hydrogen content began to decline. $7.5 \mathrm{~d}$ after start-up, litter hydrogen was produced. The hydrogen production yield of 2\#, 3\#, 4\# were $11.5,12.2,11.7 \mathrm{~mL}^{-1}{ }^{-1}$ (VS) respectively. A little gas was produced at the first day in $1 \#$, and the hydrogen content was low, Less than $30 \%$. The amount of hydrogen started to increase linearly in the second day and reach its peak at the sixth day, but the maximum rate of hydrogen production lasted no more than $2 \mathrm{~h}$. Until the 13th day the gas was too little to collected, therefore the hydrogen production period is $13 \mathrm{~d}$. hydrogen production yield is $9.2 \mathrm{~mL} \cdot \mathrm{g}^{-1}(\mathrm{VS})$. Consequently, after the sludge was treated by acid alkali treatment, the period of hydrogen production was shortened obviously, acid alkali treatment is an effective solution to the problem that the hydrogen production period is too long in sludge anaerobic digestion system. After acid pretreatment, the amount of dissolved organic in sludge increased, which is the same as the effect of alkali pretreatment. The difference between acid pretreatment and alkali pretreatment was that acid pretreatment provided methanogen a good growth condition because of the acidification of substrate and the formation of menthanogenic phase, in order to maintain the systems ability of hydrogen production, it is needed to control the $\mathrm{pH}$ value or to use methanogen inhibitor such as acetylene, BES to make the system pro-hydrogen instead of methane.

\subsection{Effect of Heat Digestion Pretreatment on Bio-Hydrogen Production}

Fig. 4 showed the amount of SCOD in 5\#, 6\#, 7\# rose linearly with the heat digestion time extended and the temperature rose. When the sludge temperature is $80 \sim 100^{\circ} \mathrm{C}$, the amount of dissolved organic increased obviously. The dissolution rate reached the peak at $93^{\circ} \mathrm{C}$, however the rate decreased when the temperature rose

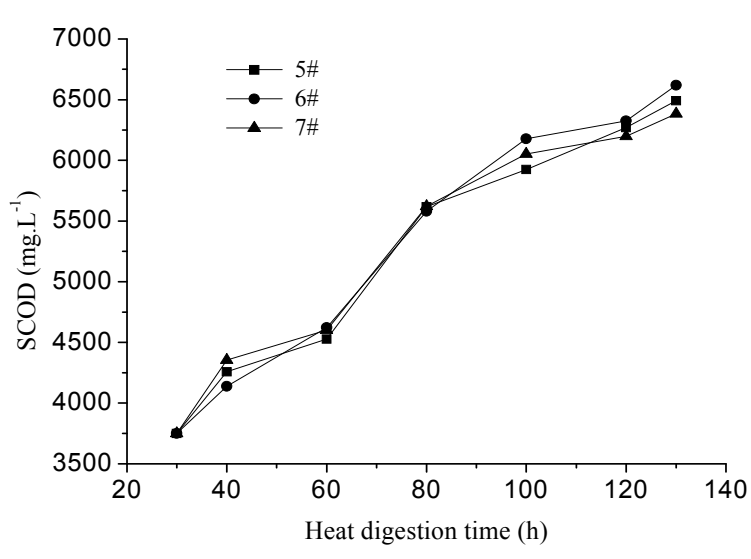

Figure 4. Change of SCOD about Sludge for heat digestion.

to $120^{\circ} \mathrm{C}$. There was refractory fiber as well as easily degradable organic in the sludge. Fig. 5 showed the structure of the fiber. When the temperature was higher than $120^{\circ} \mathrm{C}$, the fiber structure was destroyed, decomposing into cellobiose and penta-disaccharide, and then transforming into glucose, degraded by bacteria finally. Therefore, the SCOD value increased slowly. The amount of SCOD in 5\#, 6\#, 7\# were separately increased $1.73,1.76,1.70$ times. The changes of fermentative bio-hydrogen production were depicted in Fig. 6 hydrogen production of $5 \#, 6 \#, 7 \#$ increased considerablely 27 $\mathrm{h}$ after start-up, and reached the peak in 40 48h, then declined. Little gas could be collected at the 8th day, which was considered as the end of cycle period. The hydrogen production yield of $5 \#, 6 \#, 7 \#$ is $24.7,24.1$, $24.1 \mathrm{~mL}^{-\mathrm{g}^{-1}}$ (VS). Heat digestion dissolved the de-lipid of cell, weakened the tolerance ability of cell wall against heat, promoting the hydrolysis of sludge. It was observed that the color of sludge mixed liquor turned into reddish-brown, and the liquor was covered by a layer of film because of the effect of heat. the reason maybe a part of microbiology protein dissolve.

\subsection{Effects of Ultrasound Treatment on Anaerobic Sludge Digestion Hydrogen Production}

Fig. 7 illustrated changes of anaerobic sludge digestion hydrogen production. On the conditions of $\mathrm{P}=1,800 \mathrm{~W}$ and $\mathrm{f}=35 \mathrm{kHz}$, the sludge samples $8 \#, 9 \#, 10 \#$ are treated with ultrasound for $20 \mathrm{~min}$ respectively. An increase of dissolved chemical oxygen demand of sludge was observed. The rate of organic matter dissolution can be calculated by Equation (2).

$$
D D C O D=\frac{S C O D_{t}-S C O D_{t 0}-S C O D_{p H}}{T C O D-S C O D_{0}} \times 100 \%
$$

In the equation:

DDCOD—rate of organic matter dissolution, \%; 


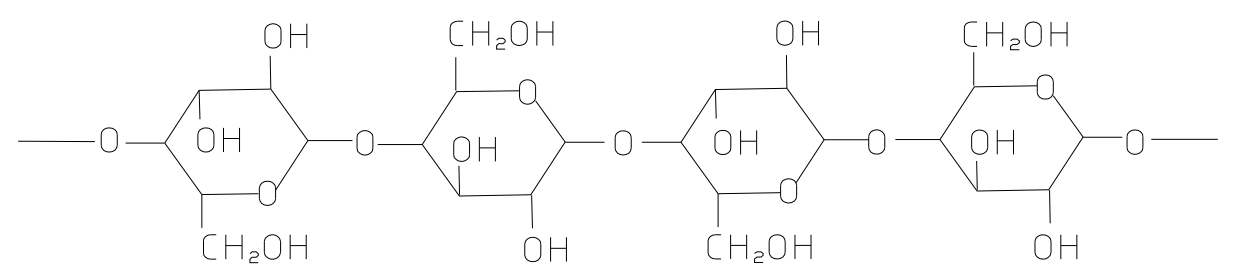

Figure 5. The schematic diagram about the structure of the cellulose.

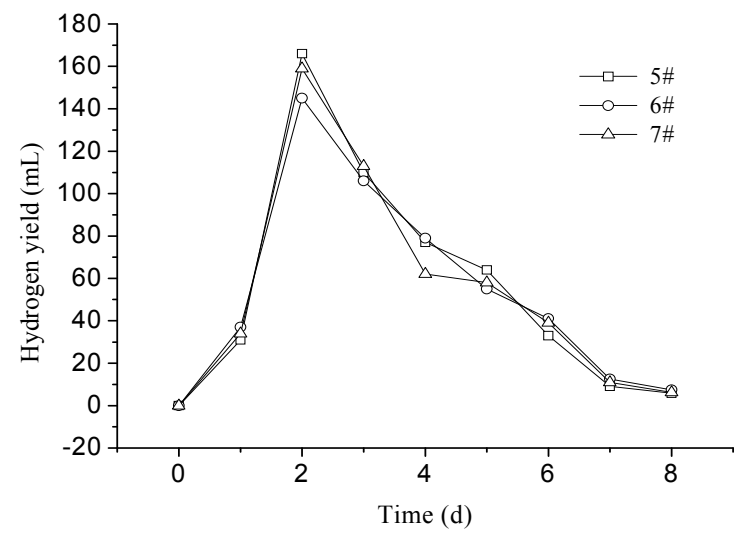

Figure 6. production hydrogen of anaerobic digestion from sludge by heat digestion.

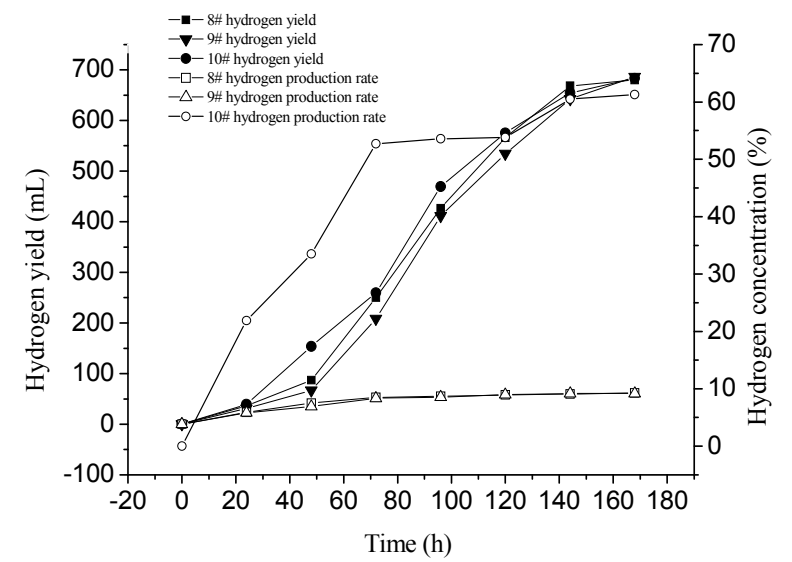

Figure 7. production hydrogen of anaerobic digestion from sludge by ultrasonic wave.

TCOD_the COD of supernatant obtained from the sludge solution, $\mathrm{mg} / \mathrm{L}$;

$\mathrm{SCOD}_{\mathrm{pH}}$ the $\mathrm{COD}$ of filtering supernatant of sludge solution under $\mathrm{pH}, \mathrm{mg} \cdot \mathrm{L}^{-1}$;

$\mathrm{SCOD}_{\mathrm{t} 0}$ the COD of supernatant obtained from the sludge solution been centrifuged, $\mathrm{mg} \cdot \mathrm{L}^{-1}$;

$\mathrm{SCOD}_{\mathrm{t}}$ the COD of filtering supernatant of sludge solution under different radiation time, $\mathrm{mg} \cdot \mathrm{L}^{-1}$.

The SCOD value was 2.70, 2.77, 2.64 times than that of $1 \#$ respectively, organic solution rate was $48 \sim 65 \%$. Adaptation time of hydrogen-producing bacteria is 17.4 $\mathrm{h}$, and logarithmic phase time is $9 \mathrm{~h}$. The growth and reproduction of microorganisms went into stationary phase after $26 \mathrm{~h}$, which has the largest biomass and the most hydrogen production. Simultaneously, hydrogen production of $8 \#, 9 \#, 10 \#$ went into the peak phase, and the production of $10 \#$ reached $210 \mathrm{~mL} \cdot \mathrm{d}^{-1}$, then the production began to decline. 7 days after start-up, hydrogen production was less than $10 \mathrm{~mL} \cdot \mathrm{d}^{-1}$ reaching almost zero at the end of the cycle period. Degradation rate of COD is more than $80 \%$, and the hydrogen production yield is $34.2,34.9,34.5 \mathrm{~mL} \cdot \mathrm{g}^{-1}$ (VS) respectively, and the methane concentration close to "zero". The analysis showed that sludge solution was affected by ultrasonic energy experience dynamic processes of vibration, growth, collapse and closure. At the moment of the collapse of the bubble, high-temperature and high pressure will be created in a very small space around the bubble, which will destruct the floceulent structure of sludge and crush the cell of microorganisms. Intermolecular hydrogen bond of Cellulose which is refractory broke by ultrasonic irradiation, producing organic matter easily biodegradable such as sugar. Consequently the dissolved organic, which provided enough carbon source for the growth and reproduction of anaerobic microbe, multiplied in sludge solution. It was also found that after ultrasonic irradiation, the permeability of cell membrane and cell wall have changed, and the looseness of extracellular polymers increased, which promoted biological masstransfer and improved the enzyme activity, so the TF (The activity of dehydrogenase was evaluated by the amount of TF which generated by the reaction between per unit mixture liquid sludge and TTC in unit time, the unit is $\mathrm{mg} \cdot \mathrm{L}^{-1} \cdot \mathrm{h}^{-1}$ ) value rose. Fig. 7 showed the change trend of dehydrogenase activity. because of the ultrasound pretreatment, the catalysis of dehydrogenase and nitrogenase etc. was improved, as well as the decomposition and absorption ability of anaerobic bacteria and facultative anaerobe [24]. Therefore the degradation of organic speed up. In the stage of peak hydrogen production lots of bio-hydrogen heterotrophic bacteria were observed, such as clostridium, enterobacter, Escherichia coli, Citrobacter, Bacillus, Thiobacillus, etc. by microscopic examination, the most bacteria were enterobacter aerogenes, candida maltose. Synergistic effect between strain is good, which inhibited the accumulation of metabolites and then provided a good environment for hydrogenogens, therefore it was given full play to hydro- 
genogens, the hydrogen production yield rose.

\subsection{Effect of Dehydrogenase Activity by Pretreatment Sludge}

Dehydrogenase activity is defined as the TF volume per unit time, with the unit $\mathrm{mg} \cdot \mathrm{L}^{-1} \cdot \mathrm{h}^{-1}$ [25]. From Fig. 8, the initial TF was $60.6 \mathrm{mg} \cdot \mathrm{L}^{-1} \cdot \mathrm{h}^{-1}$, after pretreatment $\mathrm{TF}$ were $71.2,69.9,78.8 \mathrm{mg} \cdot \mathrm{L}^{-1} \cdot \mathrm{h}^{-1}$ respectively. $12 \mathrm{~h}$ later, TF declined to $32,31.2,27.7 \mathrm{mg} \cdot \mathrm{L}^{-1} \cdot \mathrm{h}^{-1}$ respectively. The result showed Dehydrogenase activity was increased with pretreatment. the permeability of cell membrane and cell wall changed because of pretreatment, which promoted the mass transfer, the production and activity of cell enzyme, so the metabolism speeded up. Moreover, $\mathrm{NAD}+$ or NADP + regenerated by cell can absorb and transport substrate or TTC effectively, therefore the amount of TF increased [26].

\subsection{Analyzing Kinetic Model of Hydrogen Production Bacteriaons}

Fig. 3, Fig. 6, and Fig. 7 showed hydrogen production closely related to the microbial growth regularity. The change of hydrogen yield contain four phases: lag phase, beginning of hydrogen production, continuous hydrogen production and attenuation of hydrogen production. The lag phase was short $(0 \sim 11 \mathrm{~h})$. There was no hydrogen production until a stable hydrogen production flora formed after acclimation, cultivation and propagation. Subsequently, hydrogen yield increased gradually with the exponential increase of bacteria. Hydrogen content rose when the growth rate of bacteria was maximum. About $27 \mathrm{~h}$ later, the organic content of substrate declined because of the rapid bacteria propagation consuming considerable organic material. Meanwhile, the accumulation of metabolites poisoned bacteria, and bacteria death rate rose. When the growth rate balanced the death rate, the amount of bacteria in the system was maximum. After $80 \mathrm{~h}$ nutrition was exhausted, the bacte-

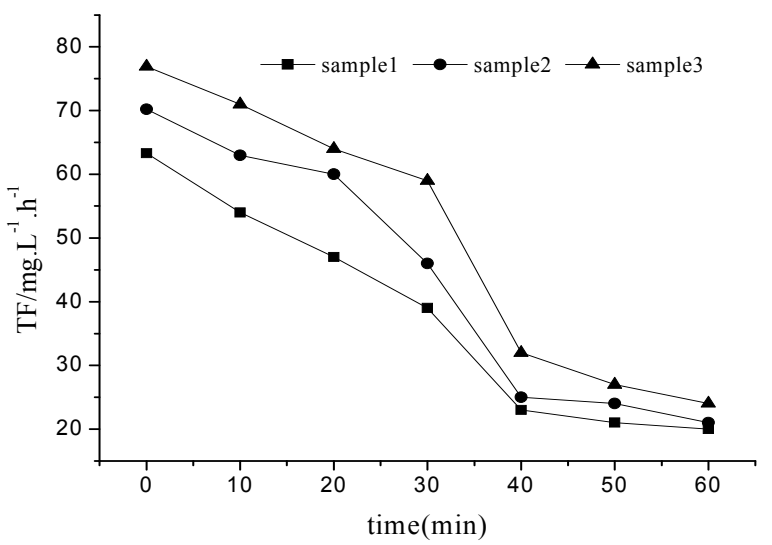

Figure 8. Variation of dehydrogenase activity with pretreatment. ria performed endogenous respiration and even formed spore, hydrogen yield declined until the end. The reaction period was about $160 \mathrm{~h}$. No methane was observed during the reaction. Gompertz model curve fitting on hydrogen production was carried out. All the values of correlation factor R2 were more than 0.97 . Therefore the fitting effect of Gompertz model on describing the biohydrogen production process was good.

\section{CONCLUSIONS}

The sludge been treated by acid and alkali, heat digestion, ultrasonic treatment, most of the refractory organic transformed into easily degradable carbohydrate. Compared with control group, the dehydrogenase activity was increased, the SCOD was increased 2.47 2.83, 1.70 1.76, 2.6 2.77 times respectively, the hydrogen production yield were 11.5 12.2, 24.1 24.7, 34.2 34.9 $\mathrm{mL} . \mathrm{g}^{-1}(\mathrm{VS})$ respectively, the period of hydrogen production was shorten to $7.5,8.0,6.5 \mathrm{~d}$ respectively. Remove of the COD was up to $72.04 \%, 81.4 \%, 80 \%$ respectively. the methane concentration in the gas was close to "zero". The hydrogen concentration can reach $99.3 \%$ after the bio-gas was purified by $\mathrm{Ca}(\mathrm{OH})_{2}$ saturated solution. Gompertz model curve fitting on hydrogen production was carried out. All the values of correlation factor R2 were more than 0.97 .

\section{ACKNOWLEDGEMENTS}

The authors wish to thank the New Century Outstanding Young Teacher Grant of the Ministry of Education of China for financial support (NCET-04-0819).

\section{REFERENCES}

[1] Liliana, M., Alzate-Gaviria, Sebastian, P. J., et al. (2007) Comparison of two anaerobic systems for hydrogen production from the organic fraction of municipal solid waste and synthetic wastewater [J]. Hydrogen Energy, 3(4), 1-6.

[2] Zabut, B., Kahlout, K. E., Yücel, M., et al. (2006) Hydrogen gas production by combined systems of Rhodobacter sphaeroides O. U. 001 and Halobacterium salinarum in a photobioreactor [J]. Hydrogen Energy, 31(11), $1553-1562$.

[3] Venkata, M. S., Lalit, B. V. and Sarma, P. N. (2007) Anaerobic biohydrogen production from dairy wastewater treatment in sequencing batch reactor (AnSBR): effect of organic loading rate $[\mathrm{J}]$. Enz Micro Technology, 3(3), $1-10$.

[4] Tan, T. W., Wang, F. and Deng, L. (2003) Present situation and prospect for bioenergy [J]. Modern chemical industry, 23(9), 8-14.

[5] Wang, Q. H., Ma, H. Z., Wang, X. M., et al. (2004) Resource recycling technology of foodwastes [J]. Modern Chemical Industry, 24(7), 56-59.

[6] Ren, N. Q., Lia, J. Z., Lib, B. K., et al. (2006) Bio-hydrogen production from molasses by anaerobic fermenta- 
tion with a pilot-scale bioreactor system [J]. International Journal of Hydrogen Energy, 31, 2147-2157.

[7] Li, Y. J., Li, A. M. and Gao, N. B. (2002) An approach to a subject of innocuous in cineration of municipal soldwaste $[\mathrm{J}]$. Journal of Shenyang Institute of Aeronautical Engineering, 19(3), 57-60.

[8] Gomez, X., Moran, A., Cuetos, M. J., et al. (2006) The production of hydrogen by dark fermentation of municipal solid wastes and slaughterhousewaste: A two-phase process [J]. Sour, 157, 727-732.

[9] Levin, D. B., Islam, R., Cicek, N. and Sparling, R. (2006) Hydrogen production by Clostridium thermocellum 27405 from cellulosic biomass substrates [J]. Hydrogen Energy, 31(11), 1496-1503.

[10] Zuo, Y., Zuo, J. N., Zhang, W., et al. (2004) A study on steady anaerobic bio-hydrogen production using river sediments as seed sludge [J]. China biogas, 22(4), 22-25.

[11] Tai, M. L. and Liu J. X. (2005) Factors of effecting hydrogen production from anaerobic fermentation of excess seweage sludge [J]. Environmental Science, 26(2), 98111.

[12] Ginkel, S. W., Oha, S.-E. and Logan, B. E. (2005) Biohydrogen gas production from food processing and domestic wastewaters $[\mathrm{J}]$. International Journal of Hydrogen Energy, 30, 1535-1542.

[13] Zhu, H. G., Parker, W., Basnar R., et al. (2008) Biohydrogen production by anaerobic co-digestion of municipal food waste and sewage sludges [J]. International Journal of Hydrogen Energy, 33, 3651-3659.

[14] Krupp, M. and Widmann, R. (2008) Biohydrogen production by dark fermentation: Experiences of continuous operation in large lab scale [J]. International Journal of Hydrogen Energy, 28, 1-8.

[15] Ela Eroglu, Inci Erolu, Ufuk Gündüzb, et al. (2006) Biological hydrogen production from olive mill wastewater with two-stage processes [J]. International Journal of Hydrogen Energy, 31, 1527-1535.

[16] Li, D. M. and Chen, H. Z. (2007) Biological hydrogen production from steam-exploded strawby simultaneous saccharification and fermentation [J]. International Journal of Hydrogen Energy, 32, 1742-1748.

[17] Zabut, B., Kahlout, K. E., Yücel M., et al. (2006) Hydrogen gas production by combined systems of Rhodobacter sphaeroides O. U. 001 and Halobacterium salinarum in a photobioreactor $[\mathrm{J}]$. International Journal of Hydrogen Energy, 31(11), 1553-1562.

[18] State Environmental Protection Administration of China (2002) Detecting methods of water and wastewater (Edition IV) [M]. Beijing, China Environmental Science Press.

[19] Zhu, N. W., Min, H., Cheng, M. C., et al. (1996) The study of Determination on TTC-Dehydrogenase Activity [J]. China Biogas, 14(2), 3-5.

[20] An, L. C., Niu, H., Zeng C., et al. (1996) A Study on the Measurement of dehydrogenase activity in activated sludge [J]. Pollution control Technology, 9(3), 186-188.

[21] Pan, C. M., Fan, Y. T., Xing, Y., et al. (2008) Statistical optimization of process parameters on bio-hydrogen production from glucose by Clostridium sp. Fanp2 [J]. Bioresour Biotechchnol, 99, 3146-3154.

[22] Lay, J. J., Lee, Y. J. and Noike, T. (1999) Feasibility of biological hydrogen production from organic fraction of municipal solid waste [J]. Wat. Res, 33(11), 2579-2586.

[23] Cai, M. L. and Liu, J. X. (2005) Factors of effecting hydrogen production from anaerobic fermentation of excess sewage sludge [J]. Environmental Science, 26(2), 97-100.

[24] Bartons, Bullock, C. and Weir, D. (1996) The effects of uktrasound on the activities of some glycosidase enzymes of industrial importance [J]. Enzyme Microbe Technology, 18(3), 190-194.

[25] Tang, N., Chai, L. Y., Min X. B., et al. (2005) Characteristic bacterial number of anaerobic activated sludge with dehydrogenase activity as indicator [J]. Journal of Microbiology, 25(2), 31-34.

[26] Jeffcres T. W. and Kurtzman C. P. (1994) Strain selection, taxonony, and genetics of xylose-fermentation yeast [J]. Enzyme Microb Technology, 16, 922-931. 